\title{
ACCESSING KNOWLEDGE IN A DISCONTINUOUS WORLD. A BRIEF COMMENT FROM SOUTHERN CHILE'
}

// MARCELO I. GONZÁLEZ GÁLVEZ

// ${ }^{1}$ This paper was written as part of the FONDECYT postdoctoral research project №3130415, entitled: 'El mundo, la realidad y el conocimiento: la versión de los mapuches'. 
would like to know what it is to be a Mapuche', I told Juan, one of the most prominent elders in Elicura, trying to explain to him the purpose of my doctoral research. Elicura is a small valley in southern Chile, where I carried out fieldwork between September 2009 and October 2010. It is inhabited by approximately 1,500 people, of which half are self-declared Mapuche, the most numerous indigenous people in Chile. As Juan was listening to my claim, he looked at me puzzled, and after a few moments he smiled and replied: 'That's impossible! You cannot know what it is to be a Mapuche. [...] The only way to know what is to be a Mapuche is to be one, so to know it you would have to be born again! [This time as a Mapuche]' Disappointed by Juan's reaction, I did not fully comprehend the depth of his assertion until a few months later. When Juan claimed the impossibility of my ethnographic effort, he did not intend to be rude or unsupportive, as he also did not point out that I could not know what is to be a Mapuche because I was an outsider who, additionally, was not a Mapuche 'racially speaking'. Rather, as I understood later, he was implicitly maintaining a twofold principle that is obvious for most rural Mapuche people I have met, and which might be explained as follows.

Firstly, Mapuche people usually uphold that any meaning of anything, even of what the term 'Mapuche' means, is deeply personal. This is regardless of those aspects one may externally and prima facie assess as 'evidently' collective. Thus, for instance, although there might be a collective of people one might externally label as 'the Mapuche', it is expected that what it is to be a Mapuche for each one of its members would be something radically different (Similarly, each personal perspective on the nature of this so-called 'Mapuche collective' would be different for those who comprise it). Although Juan thought I could not know what it is to be a Mapuche because I was not what he considered Mapuche people to be; for him, additionally, there was not even a tiny possibility that I could know what is to be Mapuche to his view. Although one could make up one's own mind about certain things given certain circumstances, any possibility of knowing what is on other peoples' minds seems, for the Mapuche, to be simply beyond discussion. This issue has several practical implications in Mapuche rural life, and it may be observed in a strong reluctance to give advice, or in the ubiquitous doubt people maintain towards what is really meant by other peoples' words (see González Gálvez 2012).

Secondly, and intimately connected to the former statement, by denying to me the possibility of understanding the other, Juan was simultaneously sharing with me one of the key principles of what can be loosely labelled as a 'Mapuche philosophy'. Although this principle may be very simple, its implications are enormous (as we will see later), and exceed by far the small aspect I address in this paper. In short, the principle states that the only way of really knowing about something is by experiencing that something yourself. It was also due to this principle that
Juan was actually one of the most renowned people in Elicura. It is common among the Mapuche, as elsewhere, to assert that some people 'know' more than others. However, in Mapuche life this cumulative and quantifiable conception of 'knowledge' is conceived of as inextricable from the several first-hand experiences that people have had in life. Thence, it is generally supposed that the older the person, the more experience he has had, and the more 'knowledge' he has accumulated. This was the reason for Juan's fame: it was simply because he was one of the oldest people living in Elicura.

In this paper I intend to problematize the idea of 'accessing knowledge', considering my ethnographic experience among the Mapuche people of southern Chile. Drawing on the aforementioned principle underlining the relevance of personal experience, I will attempt a twofold comment. The first comment refers to the 'world' which knowledge makes reference to, which involves confronting two possible understandings: the one implicit in the project ' $L a$ mia cura $^{\prime}{ }^{2}$ and the one summarised in asserting that the only way of knowing what it is to be a Mapuche is by 'being one'. The second comment refers to the potential that any knowledge has to be shared and/or accessed, which eventually involves challenging many assumptions that the idea of knowledge often implies (e.g. an intersubjective ethos). This latter comment will eventually lead us to deal with the problematic relationship between ontology and epistemology, which, as I argue, ultimately reclaims an always-contingent ethnographic solution.

\section{THE WORLD}

Since I first planned writing this piece, I wondered what my friend Juan would think about the project 'La mia cura'. In case the reader is not acquainted with it, in brief, this is a project carried out by Salvatore Iaconesi, an Italian artist who suffers from a brain tumour. Considering this, he has uploaded all his medical records to a freeaccess website, intending to share them with everybody. Through this, Salvatore aims to find a cure to his illness, which he expects to be suggested by any, some, or many of this 'everybody' looking at his files. A few times I have thought that perhaps Juan would dare to give Salvatore one possible cure, suggesting that he should take a plane to Chile in order to visit the powerful evangelical prophet who cured his wife from what she described as a 'stomach cancer'. Nevertheless, I am more inclined to think that Juan would not do that. This is not because Juan would not feel empathy for Salvatore's suffering. It is simply because, regardless of any compassion Salvatore's case may awake in Juan, he would probably think it extremely odd to find out what is good for oneself through another person's experiences. 'How can a person, who is not even related to him, know what is good for him?', Juan would probably ask. And, perhaps, Salvatore would answer:

\footnotetext{
${ }^{2}$ Inspirational piece for this issue of The Unfamiliar. See http:// www.artisopensource.net/cure/
} 
'because in the past he might have had the same illness I am now experiencing'.

In this fictional conversation lies the core of the point I want to put forward. I have the strong impression that what might be at stake here is an equivocation (sensu Viveiros de Castro 2004), involving two superficially similar references, which point to two extremely different referents. Supporting both Salvatore's and Juan's allocutions, we may discern two different premises responding, eventually, to two mutually incommensurate understandings of 'the world' (sensu Merleau-Ponty 2004). On the one hand, we have Salvatore's premise, which assumes (considering certain nuances) that there exists an overarching category (we can call it 'humanity') that is set out in an immutable setting ('the world', 'reality'), which is beyond human agency. It is nothing but this assumption that explains why it is worth sharing his medical records and why it is worth listening to other people's solutions: for Salvatore there is a given continuity (i.e. human biology) allowing the recurrence of certain phenomena (e.g. cancer), and because of this continuity it is possible to replicate certain ways of action (e.g. treatments) in order to obtain the expected results (i.e. a cure). Even though each human being is considered to be unique in a psychological sense, in this understanding there is a biological connection that brings them all together, allowing them to have the 'same' diseases and treatments.

On the other hand, we have the premise supporting the claim which, I suppose, Juan would make. In his view, contrary to Salvatore's, there is not a given continuity between different human beings (at best, this continuity must be created [González Gálvez 2012]) in the same way as there is not a transcendental unity inherent in 'the world' to be experienced. If, in Salvatore's case, there is an implicit subject/object dualism, which allows subjects to replicate their equivalent experiences of the same objects, in Juan's case such a dualism cannot even be claimed to exist (because subjects and objects do not belong a priori to 'the same' categories). Considering this, we can have a better grasp of the reasons behind Juan's assertion of the impossibility of acquiring certain knowledge (e.g. the meaning of being Mapuche): because to his view what may be labelled as 'world' and 'humanity' are discontinuous categories. What this discontinuity implies, fundamentally, is a denial of any given possibility of phenomenological replication. There is no reason to suppose one person is perceptively and substantially equivalent to another, and thus there is no reason to surmise that their personal experiences might be replicable by others. That is exactly why, to know something, each person must personally experience that something.

One immediate problem emerging from such a stance regards the notion of what so far I have called 'the world'. In Salvatore's case, due to its immutability, 'the world' appears to be frozen in ceteris paribus ('cancer', 'humanity', and 'cure' are concepts which are part of this unitary world, insofar as they are essentially independent of people), but in Juan's case the equation seems to go as follows: If the way we know what is 'out there' is by experiencing it, and if experience is something fundamentally personal, it is necessary to conclude that people do not inhabit one, but multiple worlds of experience. These multiple worlds lack, as might be expected, any necessary unity, and if they sometimes overlap, this is more due to the similarity of the people experiencing their own worlds than to an intrinsic characteristic of 'the world out there'.

\section{ACCESSING KNOWLEDGE}

Once discussed, the ontological relativity to which 'knowing' may be subdued, and taking seriously the path opened up by Juan, it seems that the questions one might ask regarding the subject of 'accessing knowledge' are very different from the ones one would ask if one takes, for example, a political approach. Indeed, following Juan, we are quite unexpectedly very far away from any sort of ethical discussion that argues against any form of restricting knowledge, and we are not even close to a celebration of any free access to it. Conversely, perhaps we may recognise ourselves discussing another dimension of topics, more related to defining knowledge in the first place. I think there are at least two critical, but interrelated, points in this sense. The first is related to challenging the social nature of knowledge, whereas the second refers to a denial of its potential for institutionalisation.

The first thing Juan's premise allows us is to challenge the notion of knowledge as an artefact, which may be traded and exchanged within social life. Even though for Juan - knowledge is something one possesses, it is not something one immediately could share, due to the strict personal nature of that knowledge. As stated above, in Juan's view what is known and what is not known is entirely up to a person, in its pure singularity. This notion brings out two subjects immediately: 1) a veil of incertitude regarding the ways (if any) that Mapuche people consider it possible to 'transmit knowledge'; ; and 2) the implications of thinking about knowledge not only as detached from its 'social nature', but also unleashed from the constraints imposed by thinking about it as a 'social artefact'. It is on this second subject that I want to focus my attention.

As stated before, thinking about 'the world' as something dependent upon each singular person posits a problem concerning the way we might think about accessing knowledge. It does not only challenge any preconceived idea of what constitutes knowledge, but it asks for a re-

\footnotetext{
${ }^{3}$ Eventually most knowledge can be partially transmitted if one follows certain ways of action, but this is a subject I deliberately chose to leave out of this argument in order to emphasise the discontinuity of the Mapuche way of thinking about 'the world'. If the reader is interested, these ways are described in González Gálvez (2012).
} 
conceptualization of the ways we think one may access any knowledge. If people cannot necessarily replicate other people's personal experiences, and if one cannot really learn anything from others (the only way of really knowing about something is experiencing that something yourself), any access to knowledge seems to be limited to each personal engagement with 'the world'. In a literal sense, accessing knowledge appears freed from any social mediation, and seems to be entirely up to each personal agency. Knowledge is, thus, no longer a social artefact, but an inalienable personal possession resulting from an open-ended personal experience.

Perhaps the most relevant outcome of this 'new' and asocial notion of knowledge is that it resists the key problem of free access to knowledge: its institutionalisation. To consider knowledge as a social artefact, which may be exchanged and transmitted, is what eventually makes it something to be restricted, valued, and commoditised. On the contrary, if we take knowledge to be an intimate and personal possession, any possible restriction or commodification of it seems nothing but absurd. Why would somebody want to restrict access to something that cannot be $u n$-restricted? (i.e. other people's knowledge-s). Why would somebody commodify something that only has value for the only person able to commodify it? Consequently, accessing knowledge is no longer a social problem but an epistemological one. Thus, we would not have to worry about the dilemmas involving the dissemination of social knowledge, and instead should introspectively consider our own personal potential to know what is good/bad for us in worlds that are entirely dependent upon that personal potential.

\section{CONCLUSION}

To conclude this brief set of comments I would like to clarify that it is not my intention to criticise the project 'La mia cura', which, regardless of what I seem to put forward in this paper, I find truly remarkable and in many ways admirable. To have employed it here is only for the sake of making a point I think of as crucial when approaching the subject of accessing knowledge from an anthropological perspective. Put simply, before dealing with a subject we must avoid taking any part of that subject for granted. If you want, before asking questions about the benefits or difficulties posited by the problem of accessing knowledge nowadays, it is compulsory (at least if one wants to keep equivocations [sensu Viveiros de Castro 2004] to a minimum) first to comprehend what is to be understood as knowledge and the means one may use to access it. In this sense, it seems that we should be constantly reviewing the relationship between ontology (what things are) and epistemology (the means employed to understand what things are). I sincerely think this relationship should be conceived as an open-ended mutual determination, which considers none of the terms involved as final and essentially established, but in a continual motion of being determined by, and simultaneously determining, the other. This implies denying the existence of an ultimate ontology and of a concurrent privileged epistemology in order to access this ontology. And, on the contrary, recognising the existence of multiple ontologies, which may be accessed and reproduced only by their own particular epistemologies. Denying the existence of one unitary and definitive ontology is nothing but breaking a continuity that we may see in 'the world', but which is not necessarily in 'the world'. Once 'the world' appears as discontinuous, we are thus forced to look at each possible ontology-epistemology relationship in particular, avoiding the imposition of our own terms on others.

This takes us, finally, to reflect about the fundamental place ethnography should enjoy, not only as a research method, but also as a means of creating relational bridges between the discontinuities of 'the world'. It is only by a deep and committed engagement between people that one may partially figure out other ontology-epistemology relationships. In anthropology, it is perhaps Martin Holbraad (2009) who lately has been most clearly maintaining this kind of stance, dismissing the classical representational approach (which assumes a natural continuity bringing together different cultures) in order to take one what he labels as 'ontographic'. Following this paper's subject, this implies that anthropology should not be about asking why Juan believes those things about knowledge, but what knowledge is in his view. However, it must be clear that none of these claims should be understood as definitive. If ontologies and epistemologies are always contingent, there is no problem at all if Salvatore looks for a cure employing whichever means he wants, as long as that means are coherent with the ontology he maintains. A problem would only arise if one assumed that the same methods and ontological assumptions are valid for everyone, including Juan, without even asking them if they are in agreement with that supposition. (ए)

\section{REFERENCES}

González Gálvez, M. (2012) Personal truths, shared equivocations. Otherness, uniqueness and social life among the Mapuche of southern Chile. PhD Thesis. University of Edinburgh.

Holbraad, M. (2009) 'Ontography and alterity. Defining anthropological truth.' Social Analysis. 53 (2): 80-93.

Merleau-Ponty, M. (2004) The world of perception. London: Routledge.

Viveiros de Castro, E. (2004) 'Perspectival anthropology and the method of controlled equivocation.' Tipití. 2 (1): 3-22. 